\title{
The Roles and Attributes of the Clinical Teacher that Contribute to Favourable Learning Environments: A Case Study from Physiotherapy
}

\begin{abstract}
The quality of clinical education is dependent on learning experiences. The clinical teacher plays a key role in successful clinical education.

The aims of the study were to determine which roles and attributes of physiotherapy clinical teachers contribute to a supportive clinical learning environment according to physiotherapy students and their clinical teachers.

The study protocol was approved by the Committee for Human Research at Stellenbosch University. A qualitative research design was used. An interview schedule was developed based on existing literature. Data was analyzed using content analysis. Data was coded, categorized and conceptualized into key themes and patterns.

All third year $(n=40)$ and fourth year $(n=40)$ undergraduate physiotherapy students and their clinical teachers $(n=37)$ were eligible to participate. Semi-structured individual interviews were conducted with a purposive sample consisting of six third-year students, six fourth-year students and six clinical teachers $(n=18)$. Written informed consent was obtained from all participants prior to the interviews.

The teacher as role model and facilitator of learning was emphasised. The attributes of the clinical teacher that created a supportive learning environment were approachability, recognising student abilities and good communication skills. The value of active involvement and individualism in learning was highlighted.

The study confirmed that the clinical teacher is pivotal in the success of a physiotherapy clinical education program. The findings agree with the large body of international literature about supportive clinical learning environments.
\end{abstract}

KEY WORDS: CLINICAL EDUCATION, TEACHING, LEARNING, PHYSIOTHERAPY.

\section{INTRODUCTION}

Clinical education forms a core part of physiotherapy training and is essential to develop clinical skills (Lekkas et al, 2007, Mbambo, 1999, Strohschein et al 2002). Kilminster et al (2007) defines the clinical educational process as the provision of guidance and feedback on personal, professional and educational development in the trainee's experience of providing appropriate patient care. The quality of the clinical learning experience is influenced by several factors. These factors influence the learning environment and have been identified as the roles and attributes of the clinical teacher (Bennet 2003, Cross 1995, Harden and Crosby 2000, Kilminster and Jolly 2000, Onuoha 1994), and the clinical instructional model used (Babyar et al 2003, Stalmeijer et al 2009, Walker and Openshaw 1994, Williams and Webb 1994). The model of clini- cal education employed (Higgs 1993, Strohschein et al 2002), student assessment (Higgs, 1993) and the health care setting (Higgs, 1993) also plays a role in creating a learning environment.

The interaction between clinical teachers and students is the strongest element in developing expertise and forming professional identity in clinical education (Laitinen-Vaananen, 2007). Furthermore, the students' relationship with the clinical teacher plays an important part in the students' clinical learning experience (Chan, 2001). The relationship between the clinical teacher and the student has been found to be a better predictor of client outcome than skill or helpfulness of the clinical teacher (Kilminster and Jolly, 2000). Higgs (1993) supports this notion by commenting that clinical teachers play a major role in ensuring entry-level competence. The clinical teacher is thus pivotal in the achievement of learning outcomes by physiotherapy students (Cross, 1995).

Several changes have taken place in the aim and delivery of physiotherapy clinical education (Mbambo 2005). The changed role of the physiotherapy clinical teacher extends beyond supervision to include being a facilitator and manager of learning (Hewson 2000, Higgs 1993). For example, Stalmeijer et al (2009) advocates a cognitive apprenticeship model for instruction, consisting of modelling, coaching, scaffolding, articulation, reflection and exploration. Thus cognitive and non-cognitive

Corresponding Author:

Mrs DV Ernstzen,

Division Physiotherapy, Faculty of Health Sciences, Stellenbosch University, South Africa. E-mail: dd2@sun.ac.za 
attributes of the clinical teacher plays a role in creating a supportive learning environment (Bannister et al, 2010).

There is a need to determine which factors affect the delivery of good clinical education in contemporary practice. In particular, the roles and attributes of clinical teachers need to be explored in order to inform clinical teachers and to guide clinical educator training programs. No previous studies on the roles and attributes of physiotherapy clinical teachers in the South African context were found. Studies focussed mainly on the needs of clinical educators (Mbambo 1999, Mothabeng 2006). Furthermore, Delany and Bragge (2009) found incongruence between the expectations that students and clinical teachers have about learning. They found that teachers described their role relating to imparting knowledge, and students required a process of facilitating learning. Hayajneh (2011) performed a critical incident study amongst nursing students in Jordania and found that the behaviours of clinical instructors identified as enhancing their learning in the clinical setting were mainly those already identified in the literature as good teaching in nursing practice. It is important to highlight that this possibility also exist in physiotherapy clinical education.

The purpose of this study was to determine undergraduate physiotherapy students and their clinical teacher perceptions of the roles and attributes of the physiotherapy clinical teacher that contributes to a supportive clinical learning environment.

\section{METHODOLOGY}

\section{Research design}

A qualitative research approach was used. Golafshani (2003) emphasizes that the qualitative research approach seeks to come to an understanding of a context specific, real world setting without manipulating the setting. The study reported on in this paper, formed part of a larger mixed method study that employed quantitative and qualitative methods. This article focuses on the second phase of the study where qualitative methodology were employed to explore the roles and attributes of the clinical teacher that contribute to a supportive learning environment.

\section{Context of the study}

The study was performed at the Division Physiotherapy, Faculty of Health Sciences (FHS), University Stellenbosch (SU), South Africa (SA). The undergraduate physiotherapy programme is a four year Bachelors degree course. During the third and fourth year of study, students transition from a classroom and practical laboratory based curriculum, to gain clinical experience at health care centres where they are supported by a clinical lecturer and physiotherapy clinicians.

\section{Participants}

All enrolled undergraduate physiotherapy students at SU who had clinical experience, and all physiotherapists involved in the clinical education of these students during 2005 were eligible to participate. Purposive sampling was used (Creswell 2003). To ensure rich data, six participants from each of the three groups (third year students, fourth year students and clinical teachers) were chosen via random number generation and were invited to participate. Table 1 provides a profile of the population and sample.

\section{Instrumentation}

Data was generated using one-to-one, semi-structured individual interviews. These interviews were conducted during the students' final clinical rotations. Topics discussed in the interviews are included in the main interview schedule given in Box 1. Probing questions were used to develop a deeper understanding of participants' accounts of learning. Interviews were conducted by the primary researcher in English or Afrikaans according to the choice of the participant.

The interviews were recorded using a digital voice recorder and was downloaded and stored on compact discs (CD) after the interviews. Each interview, lasting an average of 20 minutes, took place at the Division Physiotherapy, SU. Unique serial numbers were given to each $\mathrm{CD}$ data set. Interview data was transcribed by an independent transcriber. Participants were invited to view and comment on transcripts to assist with validation (Creswell 2003, Mays and Pope 1995).

\section{Data analysis}

The data was analyzed by the primary researcher using content analysis. The transcripts were interpreted using specific analysis strategies (Creswell 2003, Krippendorf 2004) including familiarisation with the data, interpreting the data by coding, categorizing and contextualizing texts. An external auditor, supervising the research process checked the initial coding to aid validation. The codes were then revised into final codes which were grouped into categories by the researcher in conjunction with the external auditor. Categories lead to the development of patterns and themes within the data to explore their possible relationships.

\section{Ethical considerations}

The protocol for the study was approved by the Committee for Human Research at the FHS, SU, SA. Permission to undertake the study was obtained from the Division Physiotherapy chairperson. Written informed consent was obtained from participants prior to the interviews.

\section{RESULTS}

A profile of the population and interview participants is included as Table 1.

\section{Key findings}

The key roles and attributes of the clinical teacher that influences the learning environment were identified as:

- The teacher as role model

- The clinical teacher as facilitator of learning

- The influence of the clinical teachers' dual roles of facilitator of learning and assessor of learning

- Approachability of the clinical teacher

- Interpersonal skills of the clinical teacher

- The ability of the teacher to individualise learning

- An organised clinical teacher

- A self motivated/dynamic clinical teacher 
These key roles and attributes, together with its components and substantiating verbatim quotes from the participants are represented in Table $\mathbf{2}$.

The teacher as role model for professional conduct was one of the strongest themes. The teacher was confirmed to model personal and professional skills such as interpersonal, technical and cognitive skills.

The teacher's role dual role as facilitator of learning and assessor of learning influenced the learning process. Student participants particularly focused on what the teacher requires (or would like) during the assessment of clinical competence. This aspect of wanting to please the clinical teacher could influence the students own learning goals and the goals of the clinical rotation. The teacher as assessor may hinder the openness of the learning atmosphere as students noted that they become anxious at the thought of the teacher as assessor. Students highlighted this dichotomy more than teachers did, which could indicate that clinical teachers might be unaware of the influence of this dual role on learning. The influence that these two aspects have on each other thus needs further assessment.

Approachability of the clinical teacher was the strongest attribute of the clinical teacher to create a supportive learning environment. Participants were able to determine if the clinical teacher is approachable through verbal and nonverbal communication.

\section{Box 1. Main interview schedule}

\section{Interview schedule}

\section{Opening questions}

Describe your best clinical learning/teaching session (story or incident) OR

Describe your ideal clinical learning/teaching session (story or incident)

\section{Specific probing questions}

What influence does the clinical teacher have on your learning?

-Probe for positive experiences

-Probe for negative experiences

How and why does it influence you?

What, in your view, are the characteristics of a good clinical teacher?

-Motivate your choices

Table 1: Profile of the case population and participants

\begin{tabular}{|c|c|c|c|}
\hline & $3^{\text {rd }}$ year students & $4^{\text {th }}$ year students & Clinical teachers \\
\hline \multicolumn{4}{|c|}{ POPULATION } \\
\hline Number in category & 40 & 40 & $37^{\star}$ \\
\hline \multirow[t]{2}{*}{ Gender } & 39 female & 35 female & 34 female \\
\hline & 1 male & 5 male & 3 male \\
\hline Average age (SD) & $21,53(1,78)$ years & $22,73(1,74)$ years & $37(7,51)$ years \\
\hline \multicolumn{4}{|c|}{ PARTICIPANTS } \\
\hline Number of participants & 6 & 6 & 6 \\
\hline \multirow[t]{2}{*}{ Gender } & All female & 4 female & 5 female \\
\hline & & 2 male & 1 male \\
\hline Average age (SD) & $21,83(1,33)$ years & $22,17(1,17)$ years & $34,33(5.54)$ years \\
\hline $\begin{array}{l}\text { Clinical education } \\
\text { experience }\end{array}$ & 1 year & 2 years & $1-11$ years \\
\hline
\end{tabular}

*23 clinical lecturers and 14 clinicians in this category.
Another strong theme that emerged from the interviews is the clinical teacher's personal interaction with the students. A teacher with good interpersonal skills, who is able to connect with the students, was seen as a good clinical teacher. A good clinical teacher was also thought to be responsive to what to the students have to say. Communication and teaching on the level of the students, and respect for the difference of power in the relationship were also strong components of personal interaction. The role of the teacher in ascertaining the learning needs of each student according to that student's specific level of development and experience was emphasised.

\section{DISCUSSION}

This qualitative study provides information on students' and teachers' perspectives of the teachers' role in learning production in a clinical setting, and adds to the body of knowledge on effective clinical teaching processes and practices for physiotherapy. The findings indicate that the clinical teachers' role in clinical education surpasses the role of provision of teaching and learning activities, and extends to personal and professional factors. Clinical teachers thus have a multidimensional purpose in the academic, personal and professional development of a student. The results thus confirm the findings of Chan (2001) and Hewson (2000) that the clinical teacher plays an important role in establishing an environment and atmosphere that is conducive to learning. This study may contribute to knowledge base about aligning expectations on learning and teaching between students and clinical teachers to enhance the effectiveness of clinical education, as advocated by Delany and Bragge (2009). The findings of the study is aligned with the cognitive apprenticeship model (Stalmeijer et al 2009), which advocates a clinical instructional model involving modelling, coaching, scaffolding, articulation and exploration. However, one aspect of this model, namely reflection did not feature strongly in the study and needs further exploration.

The teacher as role model was a strong theme in this study. The literature is clear on the powerful effect the teacher as a role model has on learning 


\begin{tabular}{|c|c|c|c|}
\hline \multicolumn{4}{|c|}{ Roles and attributes of the clinical teacher that contribute to a supportive learning environment } \\
\hline Key Role/Attribute & Sub-Components & Student Quotes* & Teacher Quotes* \\
\hline Role model & $\begin{array}{l}\text { Professional conduct with } \\
\text { patients, colleagues and } \\
\text { students } \\
\text { - } \quad \text { Enjoy work } \\
\text { - } \quad \text { Cares for patients, treats them } \\
\text { effectively and holistically } \\
\text { - Knowledgeable } \\
\text { - Experts in the field }\end{array}$ & $\begin{array}{l}\text { As a teacher, you have to } \\
\text { have good knowledge, your } \\
\text { techniques must be good and } \\
\text { you need to be able to give } \\
\text { positive critique. }\end{array}$ & $\begin{array}{l}\text { If the students does not think } \\
\text { you know what you are doing, } \\
\text { then they will not value what you } \\
\text { are saying or doing. } \\
\text { The student sees how you } \\
\text { work with your colleagues and } \\
\text { patients, if you are behaving } \\
\text { according to good ethics. }\end{array}$ \\
\hline Facilitator of learning & $\begin{array}{l}\text { Does not dominate the learning } \\
\text { - } \quad \text { Give the opportunity to explore } \\
\text { reasoning } \\
\text { - Helps to guide thinking } \\
\text { - } \quad \text { Provides positive affirmation } \\
\text { - Facilitates healthy group } \\
\text { dynamics }\end{array}$ & $\begin{array}{l}\text { The teacher needs to give me } \\
\text { the opportunity to reason for } \\
\text { myself, not necessarily give } \\
\text { information out rigidly. } \\
\text { I like it when the teacher gives } \\
\text { me positive feedback - then I } \\
\text { know all is not lost. }\end{array}$ & $\begin{array}{l}\text { I try to ask stimulating questions, } \\
\text { to take thinking to a deeper level. }\end{array}$ \\
\hline $\begin{array}{l}\text { Dual role: Learning } \\
\text { Facilitator and } \\
\text { Assessor }\end{array}$ & $\begin{array}{l}\text { - Clear expectations: The student } \\
\text { know what clinical teacher } \\
\text { expects } \\
\text { - Can lead to student anxiety }\end{array}$ & $\begin{array}{l}\text { I try to find out what the teacher } \\
\text { expects and how they think, } \\
\text { because she is ultimately going } \\
\text { to assess you. } \\
\text { I am sometimes scared to } \\
\text { make mistakes, as I know the } \\
\text { teacher is going to assess me. }\end{array}$ & $\begin{array}{l}\text { This aspect can create } \\
\text { confusion. }\end{array}$ \\
\hline Approachable & $\begin{array}{ll}\text { - } & \text { Not being prejudiced } \\
\text { - } & \text { Freedom to ask questions } \\
\text { - } & \text { Open door policy } \\
\text { - } & \text { Interested in the student as } \\
\text { - } & \text { Carson for individual } \\
\text { - } & \text { Making time for student } \\
\text { - } & \text { Non threatening } \\
\text { - } & \text { Willing to help }\end{array}$ & $\begin{array}{l}\text { The clinical teacher should be } \\
\text { approachable. She needs to } \\
\text { create an open atmosphere } \\
\text { where I can easily talk about my } \\
\text { concerns. }\end{array}$ & $\begin{array}{l}\text { Students should not be scared to } \\
\text { ask you something. They need } \\
\text { to be free to make mistakes in a } \\
\text { protected environment. }\end{array}$ \\
\hline Individualisation & $\begin{array}{l}\text { - Ascertain learning needs of } \\
\text { individual student } \\
\text { - } \quad \text { Individual planning for learning } \\
\text { - } \quad \text { Show interest and care to the } \\
\text { struggling student }\end{array}$ & $\begin{array}{l}\text { It is good if the teacher could } \\
\text { 'diagnose' the students learning } \\
\text { needs, to give an idea of where } \\
\text { we need to develop. }\end{array}$ & $\begin{array}{l}\text { It is important to get to know the } \\
\text { student, to ascertain what the } \\
\text { student can and cannot do, and } \\
\text { also his perception of his skills. } \\
\text { From there, you can assist the } \\
\text { student on an appropriate level. }\end{array}$ \\
\hline Organisation & $\begin{array}{l}\text { - An orientation program is } \\
\text { important } \\
\text { - Diagnose strengths and } \\
\text { weaknesses } \\
\text { - Clarification of expectations }\end{array}$ & $\begin{array}{l}\text { The first two days is important } \\
\text { in the clinical block. A step for } \\
\text { step approach on how to go } \\
\text { about managing the clients is } \\
\text { useful. }\end{array}$ & $\begin{array}{l}\text { A good orientation program, } \\
\text { where expectations are clarified, } \\
\text { and administrative aspects are } \\
\text { dealt with, helps the students to } \\
\text { focus on learning. }\end{array}$ \\
\hline $\begin{array}{l}\text { Self motivated/ } \\
\text { Dynamic }\end{array}$ & $\begin{array}{ll}\text { - } & \text { Enthusiastic } \\
\text { - } & \text { Articulate }\end{array}$ & $\begin{array}{l}\text { A good clinical teacher is an } \\
\text { enthusiastic person who can be } \\
\text { assertive towards the student } \\
\text { and can take leadership. }\end{array}$ & $\begin{array}{l}\text { It is good to be enthusiastic } \\
\text { and show that you enjoy the } \\
\text { profession. }\end{array}$ \\
\hline
\end{tabular}

*Some quotes have been translated form Afrikaans to English for the purpose of this manuscript. 
(Bandura, 1986 in Schunk, 2004, Harden and Crosby 2000). Role modelling is a powerful means of teaching values, attitudes and patterns of thought and behaviour in the social cognitive theory of Bandura, (1986 in Schunk, 2004). The clinical teacher is perceived as a role model of health care provider in the sphere of communication with the patient, caring for the patient and knowledge dissemination. Students particularly observed the teacher's attitude and skills toward teaching, and the way the teacher manages the patient.

The teacher as assessor of learning is an integral and important role of the clinical teacher (Harden and Crosby, 2000). However, the findings of the study indicate that the dual role of the clinical teacher as facilitator of learning and assessor of learning could have detrimental effect on the atmosphere of learning, the learning process and the learning goals of the student and programme. The findings above emphasises the need for clinical teachers to create an open atmosphere of trust, where students can learn from their mistakes. The influence that assessment has on learning in this context needs to be further explored.

Student and teacher participants valued facilitation of learning and individualism as an important part of creating a supportive learning environment. In view of the participants, facilitating learning signify assisting the student at his or her point of need. This finding concurs with that of Delany and Bragge (2009), who found that the clinical teachers in their study responded to the levels of knowledge and skill of the student and adapted their guidance to be in line with the student needs. This notion also concurs with the concept of task maturity (confronting the student with a task that is on his competency level) (Higgs (1992) and scaffolding (providing appropriate building blocks for learning for an individual) (Bandura, 1986 in Schunk, 2004, Stalmeijer et al 2009).

The participants in this study suggested that facilitation of learning be utilised as gentle guiding towards an outcome, where the student is given sufficient opportunity to be involved. This need for active participation in learning and thus articulation was expressed by students in this study as well as by participants in studies by Laitinen-Vaananen (2007) and Stalmeijer et al (2009). Students want to be recognised for their abilities and contribution to patient care (Hayajneh 2011). In the current study, recognition of abilities is manifested when teachers do not dominate learning sessions, but facilitates learning sessions, giving the student the opportunity to explore. A dominant clinical teacher who takes over procedures inhibits initiative and decreases motivation (also supported by Williams and Webb, 1994). This study found that clinical teachers' recognition of students' abilities, expressed through giving positive feedback, had a powerful effect on the motivation of students.

Students valued the personal attention they received from the teacher. Nursing students, in a study by Chan (2001) also found this aspect valuable in enhancing the learning process. Furthermore, Williams and Webb (1994) found that a personal relationship with the clinical teacher who demonstrates empathy, encouragement and care, assisted learning better than any other attribute. Clinical teachers who recognise students as team members and display the qualities of encouragement and support were perceived as providing a supportive learning atmosphere. The consequence of such a learning environment might be rich personal growth as the student and teacher function as a team to achieve learning and personal goals.

The attributes that formed the strongest themes in this study was approachability, interpersonal skills and recognising student abilities. These three factors, together with individualism could be interdependent on each other. Cross (1995) identified approachability as the most important attribute of the clinical teacher. The participants in the study understood approachability to mean the creation of a learning atmosphere where students are free to ask questions without feeling threatened. Approachability contributes to a learning atmosphere that is risk free (Hewson, 2000).

\section{Implications for practice}

The findings of this study may guide clinical education training programmes for clinical teachers. It may contribute to the alignment of student and clinical teacher expectations, therefore enhancing the clinical education process. The findings of the study highlight the notion that the teacher's approach to the student and the learning situation plays an important part in facilitating learning. Clinical teachers should be aware of the powerful role they play in student learning. This role includes the provision of teaching and learning activities, as well as personal and professional development.

\section{Limitations}

A number of limitations need to be considered which could impact the interpretation and generalisability of the study. It should be acknowledged that, at the time of the study, the researcher was a lecturer in the Division Physiotherapy and this aspect could have played a role in the responses of the interviewees. However, due to the similarity of findings of this study with international literature, this aspect seemed to have had a limited effect. Participants in the study could only reflect on learning experiences and clinical teachers to which they were exposed to. Thus the study findings can only be generalized to similar contexts. A more diverse exposure to teachers and activities may provide other findings. Most of the participants were female, and a gender bias could thus exist. Furthermore, the study focussed on the clinical teachers' influence on learning, but a more holistic study which includes the students own personal and professional factors that affects development is advisable.

\section{CONCLUSION}

The study confirmed that the clinical teacher is pivotal in the success of a physiotherapy clinical education program. A good physiotherapy undergraduate clinical teacher is thus a person who models professionalism, expertise and holistic care to both the patient and the student, and assist the student as an individual to develop academically and professionally. The finding of this study agrees with the large body of international literature about supportive clinical learning environments. 
However, this study indicates that the dual role of clinical teacher as facilitator of learning and assessor of learning needs further assessment.

\section{Funding}

The Fund for Innovation and Research into Teaching and Learning, Centre for Teaching and Learning, Stellenbosch University, South Africa.

\section{Acknowledgements}

The authors would like to thank the participants for their time and input.

\section{Ethical approval}

Committee for Human Research at the Faculty of Health Sciences, Stellenbosch University, South Africa (reference number N05/08/144).

\section{REFERENCES:}

Babyar S, Rosen E, Sliwinski M, Krasilovsky G, Holland T, Lipovac M 2003 Physical Therapy Students' self-reports of development of clinical reasoning. Journal of Allied Health 32:227-239

Bannister S, Raszka W, Maloney C 2010 What makes a great clinical teacher in Pediatrics? Lessons learnt from the literature. Pediatrics, 125(5):863-865

Bennet R 2003 Clinical Education: Perceived abilities/qualities of clinical educators and team supervision of students. Physiotherapy 89:432-440

Chan DSK 2001 Combining qualitative and quantitative methods in assessing hospital learning environments. International journal of nursing studies 38:447-459

Creswell JW 2003 Research design. Qualitative, quantitative and mixed methods approaches, 2nd edn. Sage, Los Angeles

Cross V 1995 Perceptions of the ideal Clinical Educator in Physiotherapy Education. Physiotherapy 81:506-513

Delany C, Bragge P 2009 A study of physiotherapy students and clinical educators perceptions of learning and teaching. Medical Teacher 31:e402-e411

Golafshani N. 2003 Understanding Validity and Reliability in Qualitative research. The Qualitative Report 8:597-607
Harden RM, Crosby JR 2000 AMEE Guide no 20: The Good Teacher is more than a Lecturer the twelve roles of the teacher. Medical Teacher 22:334-347

Hayajneh F 2011 Role model clinical instructor as perceived by Jordanian nursing students Journal of Research in Nursing, 16(1):23-32

Hewson, MG. 2000. A theory based Faculty Development Program for Clinician-Educators Academic Medicine, 75:498-501.

Higgs J 1992 Managing clinical education: The educator manager and the self-directed learner. Physiotherapy 78:822-828

Higgs J 1993 Managing Clinical Education: The Programme. Physiotherapy 79:239-246

Kilminster SM, Jolly BC 2000 Effective supervision in clinical practice settings: a literature review. Medical Education 34:827 - 840

Kilminster S, Cottrell D, Grant J, Jolly B 2007 AMEE Guide No. 27: Effective educational and clinical supervision. Medical Teacher 29:2-19

Krippendorff K 2004 Content analysis. An introduction to its methodology. Sage, Thousand Oaks

Laitinen-Vaananen S, Talvitie U, Luukka MR 2007 Clinical supervision as an interaction between the clinical educator and the student. Physiotherapy Theory and Practice 23:95-103

Lekkas P, Larsen T, Kumar S, Grimmer K, Nyland L, Chipchase L, Jull G, Buttrum P, Carr L, Finch J 2007 No model of clinical education for physiotherapy students is superior to another: a systematic review. Australian Journal of Physiotherapy 53:19-28

Mays N, Pope C 1995 Qualitative Research Rigour and qualitative research. British Medical Journal 311:109-112

Mbambo NP 1999 Physiotherapy Clinical educators needs. South African Journal of Physiotherapy 55:16-19

Mbambo NP 2005 The changing role of Physiotherapy in South Africa. South African Journal of Physiotherapy 61:2-6

Mothabeng DJ 2006 An analysis of Pedagogic Research in Physiotherapy Education. South African Journal of Physiotherapy 62:14-18

Onuoha ARA 1994 Effective clinical teaching behaviors from the perspectives of students, supervisors and teachers. Physiotherapy 80:208-214.
Schunk DH 2004 Learning Theories. An Educational Perspective, 4th edn. Pearson Education Inc., New Jersey

Stalmeijer R, Dolmans D, Wolfhagen I, Scherpbier A 2009 Cognitive apprenticeship in clinical practice:can it stimulate learning in the opinion of students? Advances in Hwalth Science Education $14: 535-546$

Strohschein J, Hagler P, May L 2002 Assessing the need for change in Clinical Education practices. Physical Therapy 82:160 - 172

Walker EM, Openshaw S 1994 Educational Needs as perceived by Clinical Supervisors. Physiotherapy 80:424-431

Williams PL, Webb C 1994 Clinical supervision skills: A Delphi and Critical Incident Technique study. Medical Teacher 16:139 - 158 